\title{
MULHERES PROPRIETÁRIAS NAS CAPITANIAS DO NORTE, SÉCULOS XVII-XVIII: BALANÇO HISTORIOGRÁFICO E APONTAMENTOS
}

Ana Lunara da Silva Morais ${ }^{1}$

Os estudos sobre gênero como o compreendemos na atualidade teve seus contornos mais marcantes a partir da década de 1960 em um contexto de transformações das normas sociais e culturais, de desenvolvimento da teoria feminista $e$ tomada destes saberes pelos meios acadêmicos ${ }^{2}$. Trata-se de um campo interdisciplinar que busca compreender o gênero enquanto organização social da diferença sexual ${ }^{3}$, ou seja, das complexas relações e construções sociais entre o feminino e o masculino.

Nas últimas décadas, pesquisadores e pesquisadoras articularam a temática do gênero com a Nova História, a qual tinha por objetivo maior uma história social, na qual os oprimidos ganhariam voz, de forma direta ou indireta ${ }^{4}$. É neste sentido que, desde os anos 1990, surgiram inúmeros centros de estudos de gênero em reputadas universidades de todo o mundo e se organizaram vários eventos internacionais sobre o tema, todos mobilizados com questóes atuais sobre as diversas perspectivas em que é possível colocar o tema.

Das várias possibilidades de estudo sobre gênero, destacar-se-ão neste ensaio algumas aproximações de recentes pesquisas que visam explicar a reprodução social de famílias da nobreza da terra ao longo dos séculos XVII e XVIII na América portuguesa. Neste seguimento, optou-se por analisar o papel das mulheres ao que diz respeito à manutenção social do grupo, sobretudo, nas questões de reprodução material. Para tal efeito, serão apontados, de forma sucinta, os estudos sobre gênero realizados para a América portuguesa e, em seguida, de forma mais específica, os estudos produzidos sobre a posse de bens por parte de mulheres, principalmente nas capitanias do Norte (Pernambuco, Itamaracá, Paraíba, Rio Grande do Norte e Ceará) do Estado do Brasil ${ }^{5}$.

\footnotetext{
${ }^{1}$ Doutoranda em História pela Universidade de Évora, Portugal. Bolsista Capes. E-Mail: <lunara_ana@ hotmail.com>.

2 SOIHET, Rachel. "História das mulheres". In: CARDOSO, Ciro Flamarion \& VAINFAS, Ronaldo (orgs.). Domínios da História: ensaios de teoria e metodologia. 5. ed. Rio de Janeiro: Campus, 1997, p. 399-429.

${ }^{3}$ SCOTT, Joan Wallach. "Gender: a useful category of Historical Analysis". The American Historical Review, vol. 91, n. 5, 1986.

${ }^{4}$ DOSSE, François. A história em migalhas: dos Annales à Nova História. Tradução de Dulce A. Silva Ramos. 2. ed. São Paulo: Ensaio; Campinas: Editora da UNICAMP, 1994.

${ }^{5}$ Trata-se das capitanias de Pernambuco, Itamaracá, Paraíba, Rio Grande [do Norte], e Ceará. A introdução do termo "Capitanias do Norte" em substituição a "capitanias anexas a Pernambuco" faz jus aos novos debates sobre a jurisdição daquela localidade. É utilizado com objetivo de não generalizar as distintas jurisdições e suas respectivas durações que Pernambuco possuía com relação às capitanias arroladas. MENEZES, Mozart Vergetti de. "Jurisdição e poder nas Capitanias do Norte (1654-1755)". Sæculum - Revista de História, João Pessoa, n. 14, jan./jun. 2006, p. 11-25.
} 


\section{Os Estudos de Gênero para a América Portuguesa}

Os estudos de gênero para a América portuguesa possuem temas diversos, sendo vários deles ainda pouco desenvolvidos. Podemos apontar quatro grandes núcleos temáticos relacionados entre si para os meios rurais e urbanos: Mulheres na economia e trabalho; Mulheres e religiosidade; Mulheres e família; Mulheres e sexualidade, entre outros.

A inserção das mulheres no mundo do trabalho na América portuguesa tem sido pouco desenvolvida. Maria Odila Dias analisou o papel das mulheres das classes oprimidas, livres, escravas e forras, na busca por sobreviver através do trabalho cotidiano em meio ao incipiente processo de urbanização da cidade de São Paulo, desde o final do século XVIII até a segunda metade do século XIX ${ }^{6}$. A vida das mulheres escravas e forras nas Minas Gerais do século XVIII, atuantes no comércio como quitandeiras, doceiras, lavadeiras, e rendeiras, foi estudada por Luciano Figueiredo e Ana Magaldi. Demonstraram as várias facetas das atuações destas mulheres, como a simultaneidade de atuações, evidenciando objetivos e contextos diferenciados por parte destas mulheres ${ }^{7}$. Para o caso da cidade de Natal, Myriane Albuquerque analisou as mulheres no espaço público daquela localidade e evidenciou que as mulheres eram vigiadas pelo Senado da Câmara de Natal e que eram toleradas somente pelo seu envolvimento nas atividades econômicas locais ${ }^{8}$.

Pesquisas sobre a vida religiosa feminina foram desenvolvidas por historiadoras que se focaram em perceber a dinâmica de atuação destas mulheres para explicar os múltiplos significados e possibilidade de ações das mesmas. Maria José Nunes viabilizou por meio da análise das atuações das freiras entre os séculos XVII e XX, uma percepção destas enquanto indivíduos dotados de agência, com possibilidades de reflexão e ação para além das normas perpetradas pela pertença a uma congregação religiosa?.

As mulheres reclusas em conventos e recolhimentos também foram objeto de análise. Estas teriam conseguido reverter alguns dos propósitos punitivos $e$ supostamente opressivos destas instituições. Muitas religiosas perceberam que no espaço religioso se desenhava a possibilidade de uma vida autônoma, frente aos rigores da família e da sociedade, inclusive permitindo o exercício do poder. Os

${ }^{6}$ DIAS, Maria Odila Leite da Silva. Quotidiano e poder em São Paulo no século XIX. 2. ed. São Paulo: Brasiliense, 1995.

${ }^{7}$ FIGUEIREDO, Luciano Raposo de Almeida. "Mulheres nas Minas Gerais". In: DEL PRIORE, Mary (org.) \& BASSANEZI, Carla (coord.). História das Mulheres no Brasil. São Paulo: Contexto; Editora da UNESP, 1997, p. 141-188. FIGUEIREDO, Luciano Raposo de Almeida \& MAGALDI, Ana Maria Bandeira de Mello. "Quitandas e quitutes: um estudo sobre rebeldia e transgressão femininas numa sociedade colonial". Caderno de pesquisa: São Paulo, n. 54, 1985, p. 50-61.

${ }^{8}$ ALBUQUERQUE, Myriane Carla Oliveira de. As mulheres no espaço público de Natal: "daninhas" e "mal procedidas". Monografia (Graduação em História). Universidade Federal do Rio Grande do Norte. Natal, 2005.

9 NUNES, Maria José F. Rosado. "As religiosas e o compromisso com os pobres no Brasil". In: MARCÍLIO, Maria Luiza (org.). A mulher pobre na História da Igreja Latino-Americana. São Paulo: Paulinas, 1984. NUNES, Maria José F. Rosado. "A vida religiosa feminina durante a metade do século XX". Revista Expedições, vol. 5, n.2, jul./dez. 2014. NUNES, Maria José F. Rosado. "Freiras no Brasil". In: DEL PRIORE \& BASSANEZI. História das Mulheres..., p. 482-509. 
trabalhos de Suely Almeida, Leila Mezan Algranti e Mayra Guapindaia pautam-se nesta linha ${ }^{10}$.

O número de trabalhos sobre a mulher e a família tem aumentado significativamente devido ao crescimento das pesquisas sobre família e reprodução social, sobretudo no âmbito da antropologia e sociologia ${ }^{11}$. As pesquisas desta temática para a América portuguesa têm sugerido uma heterogeneidade de modelos de casamentos e de reprodução social levando em consideração a diversidade de estratos sociais e variações regionais ${ }^{12}$. Historiadores e historiadoras estudaram: os diferentes estatutos jurídicos $e$ as práticas contraditórias acerca do direito sucessório $e$ familiar no período pombalino e pós-pombalino ${ }^{13}$. A condição da maternidade também foi destacada em vários aspectos: sobre os filhos enjeitados e expostos ${ }^{14}$; maternidade irregular ${ }^{15}$; e sobre as mentalidades acerca da maternidade ${ }^{16}$.

A temática da mulher e sexualidade na América portuguesa possui várias ramificações, todavia, podemos dizer de forma genérica que historiadores $e$ historiadoras têm pesquisado sobre as normas existentes naquela sociedade sobre a sexualidade, fossem estas jurídicas ou costumeiras, $e$ as práticas adotadas pelos agentes coloniais, ou seja, suas arbitrariedades. Neste sentido, são inúmeras as pesquisas que se fazem dentro deste tema ampliando a complexidade das relações $e$ atuações das mulheres na sociedade colonial: O cotidiano feminino entre os índios do

${ }^{10}$ ALMEIDA, Suely Creusa Cordeiro de. O sexo devoto: normatização e resistência feminina no Império Português - XVI-XVII. Tese (Doutorado em História). Universidade Federal de Pernambuco. Recife, 2003. ALGRANTI, Leila Mezan. Honradas e devotas: mulheres da Colônia - Condição feminina nos conventos e recolhimentos do Sudeste do Brasil, 1750-1822. Rio de Janeiro: José Olympio; Brasília: Editora da UnB, 1993. GUAPINDAIA, Mayra Calandrini. Instituições educacionais e relações de gênero no período da ilustração portuguesa: o Recolhimento de Nossa Senhora da Glória e o Seminário de Olinda. Dissertação (Mestrado em História). Universidade de Brasília. Brasilia, 2013.

${ }^{11}$ São várias e diversas as pesquisas referentes ao tema. Listam-se aqui algumas que são norteadoras para a compreensão do tema: BOUCHARD, G. "Les systèmes de transmission des avoirs familiaux et le cycle de la société rurale au Québec du XVII au XXe siècle". Histoire sociale - Social History, vol. 16, n. 31, 1983, p. 35-60. BOURDIEU, Pierre. "Les stratégies matrimoniales dans le système de reproduction". Annales, vol. 27, n. 4-5, 1972, p. 1105-1127. BOURDIEU, Pierre. Razões práticas: sobre a teoria da ação. Tradução de Mariza Corrêa. Campinas: Papirus, 1996; VIRET, J. L. "La réproduction familiale et sociale en France sous l'Ancien Régime: le rappor au droit et aux valeurs". Histoire et sociétés rurales", n. 29, 2008, p. 165-188.

${ }^{12}$ SILVA, Maria Beatriz Nizza da. História da família no Brasil Colonial. Rio de Janeiro: Nova Fronteira, 1998. SILVA, Maria Beatriz Nizza da. Sistema de casamento no Brasil colonial. São Paulo: EDUSP, 1984.

${ }^{13}$ WEHLING, Arno \& WEHLING, Maria José. "O Direito de Família no mundo luso-brasileiro, períodos pombalino e pós-pombalino". In: SILVA, Maria Beatriz Nizza da (coord). Sexualidade, família e religião na colonização do Brasil. Lisboa: Livros Horizontes, 2001, p. 155-162. ZANNATA, Aline Antunes. Justiça e representações femininas: o divórcio entre a elite paulista (1765-1822). Dissertação (Mestrado em História). Universidade Estadual de Campinas. Campinas, 2005.

${ }^{14}$ VENÂNCIO, Renato Pinto. "Maternidade negada". In: DEL PRIORE \& BASSANEZI, História das Mulheres..., p. 189-222.

15 ARAÚJO, Renata Pedroso de. "Ser mãe na colônia: A condição da mulher sob o aspecto da maternidade irregular (Séculos XVII e XVIII)". KLEPSIDRA - Revista Virtual de História, vol. 10, 2002, p. 35-41. Disponível em: <http://www.klepsidra.net/klepsidra10/mulheres.html>.

${ }^{16}$ DEL PRIORE, Mary. Ao sul do corpo: condição feminina, maternidades e mentalidades no Brasil colônia. Rio de Janeiro: José Olympio, 1993. 
Brasil, principalmente entre os tupinambás ${ }^{17}$; a homossexualidade e a repressão inquisitorial ${ }^{18}$; o erotismo feminino ${ }^{19}$; prostituição e concubinato ${ }^{20}$.

A emergência dessas pesquisas, além de muitas outras ${ }^{21}$, demonstram a complexidade da história das mulheres na América portuguesa. Ao estudarem diversos recortes temporais, espaciais e de diferentes temáticas e, sobretudo, pela análise das mulheres de múltiplos estratos sociais, os pesquisadores e pesquisadoras propiciaram um olhar mais cuidadoso ao que se refere às análises sobre as diversas atuações das mulheres. Trata-se da necessidade de analisar o gênero com maior prudência para não serem generalizadas ideias dicotômicas como: rebelde ou vítima; obedientes ou transgressoras; ricas (nobres ou aristocratas) ou escravas (trabalhadoras), dilatando suas averiguações em fatos observáveis, de forma científica, quebrando os mitos sociais construídos. A mulher na América portuguesa não se tratava de um grupo homogêneo, mas sim plural, devendo ser considerado os diversos condicionantes de suas ações: região, riqueza, posição social, possibilidades de ascensão e promoção social e ainda desejos pessoais.

Todavia, ainda faz-se necessário chamar a atenção para que historiados, sociólogos, e antropólogos libertem-se da ideia de que toda a ação humana é permeada por uma intencionalidade. Norbert Elias alertou que os processos sociais são relativamente autônomos das intenções humanas e dos intentos que estas

${ }^{17}$ RAMINELLI, Ronald. "Eva Tupinambá". In: DEL PRIORE \& BASSANEZI, História das Mulheres...

${ }^{18}$ SILVA, Maria Beatriz Nizza da. "Mulheres na inquisição no fim do período colonial: rés e vítimas". In: SILVA, Sexualidade, família..., p. 103-112; VAINFAS, Ronaldo. "Homoerotismo feminino e Santo Ofício". In: DEL PRIORE \& BASSANEZI, História das Mulheres..., p. 115-140.

${ }^{19}$ ARAÚJO, Emanuel. "A arte da sedução: sexualidade feminina na colônia". In: DEL PRIORE \& BASSANEZI, História das Mulheres...., p. 45-77. DEL PRIORE, Mary. A mulher na história do Brasil: raízes históricas do machismo brasileiro, a mulher no imaginário social. São Paulo: Contexto, 1989. DEL PRIORE, Mary. Histórias íntimas: sexualidade e erotismo na História do Brasil. São Paulo: Editora Planeta do Brasil, 2011. DEL PRIORE, Mary. "Magia e medicina na colônia: o corpo feminino". In: DEL PRIORE \& BASSANEZI, História das Mulheres..., p. 78-114. VAINFAS, Ronaldo. "Moralidades brasilicas: deleites sexuais e linguagem erótica na sociedade escravista". In: SOUZA, Laura de Mello (org.). História da vida privada no Brasil - Vol. 1: cotidiano e vida privada na América portuguesa. São Paulo: Companhia das Letras, 1998, p. 221-273.

${ }^{20}$ CAMPOS, Kátia Maria Nunes. "Mulheres coloniais: esposas e concubinas numa sociedade Escravista". In: XVII Encontro Nacional de Estudos Populacionais. Caxambu- MG. Brasil, de 20 a 24 de setembro de 2010; KARASCH, Mary. "Concubinato e casamento na Capitania de Goiás". In: SILVA, Sexualidade, família..., p. 91-102; WEHLING, Arno; WEHLING, Maria José. "Família: casamento e divórcio, concubinato e prostituição". In: Formação do Brasil Colonial. Rio de Janeiro: Nova Fronteira, 1994.

${ }^{21}$ Também foram produzidos outros ensaios sobre a temática do gênero para a América portuguesa que não se encaixam diretamente nas subáreas anteriormente destacadas: educação feminina, imaginário sobre as mulheres na colônia, estudos do corpo da mulher; rapto e violação; honra e reputação; $e$ trajetórias singulares. TOMÉ, Dyeinne Cristina; QUADROS, Raquel dos Santos. "A educação feminina durante o Brasil colonial". In: Anais da Semana de Pedagogia da UEM, vol. 1, n. 1. Maringá: UEM, 2012; SILVA, Letícia Ferreira da \& CASTILHO, Maria Augusta de. "Brasil colonial: as mulheres e o imaginário social”. Cordis, São Paulo, n. 12, 2014, p. 257-279. AGUIAR, Marcos Magalhães de. "Rapto, violação e sedução de mulheres na Capitania de Minas". In: SILVA, Sexualidade, família..., p. 49-64; NAZZARI, Muriel. "Sem perda da honra: a preservação da reputação feminina no Brasil colonial". In: SILVA, Sexualidade, família..., p. 65-76; FURTADO, Júnia Ferreira. "Chica da Silva: o mito pelo avesso". In: SILVA, Sexualidade, família..., p, 77-90. 
buscariam $^{22}$. Por vezes as interconexões estabelecidas pelos seres humanos não possuem finalidades concretas. As conexões só passam a ter um sentido quando os indivíduos que as formam as identificaram e reconheceram, passando a lhes atribuir sentido, percebendo-se, portanto, como pessoas inter-relacionadas a outras $-e$ a outros grupos - $e$ com o poder de alcançar determinados objetivos. Nesse sentido, busca-se aqui compreender as mulheres posseiras e gestoras de bens como resultado de uma vasta sequência de significados atribuídos ao seu papel de individuo componente da família, de uma unidade compósita ${ }^{23}$, e não somente enquanto precursoras de direitos igualitários entre gêneros.

Uma dessas unidades compósitas que podem ser citadas como exemplo é a família. As relações familiares de solidariedade e interdependência podem ser encontradas em várias estâncias da sociedade da América portuguesa, por exemplo, quando se trata de transmissão de patrimônios materiais e imateriais. Para Elias, "[...] o poder é uma característica estrutural das relações humanas." e é o que rege as ações inter-relacionadas dos participantes ${ }^{24}$. Sesse sentido, compreender-se-á as mulheres neste artigo enquanto integrantes de uma unidade compósita, uma família, a qual, por sua vez, era um elemento relacional que podia imanar e emanar poder.

\section{Mulheres Proprietárias na América Portuguesa}

Cabe apontarmos aqui brevemente o debate no qual se insere o tema do patrimônio, e por consequência, da propriedade, e o que compreendemos por esta. Para compreender as diferentes formas de acumulação e manutenção de bens e das estratégias utilizadas pelos diferentes indivíduos na América portuguesa tem-se que o modelo de propriedade moderna, predominante na sociedade, sobretudo a partir do século XIX, é apenas um modelo proprietário, que pode conviver com outros. Neste sentido, há diferentes modelos proprietários, pois propriedade seria antes de tudo mentalidade $e^{25}$, não podendo constituir-se somente em uma regra técnica, sendo uma resposta ao eterno problema da relação entre homens e coisas. Além disso, como a propriedade é fruto da mentalidade de determinado sujeito de determinado período, as mudanças de mentalidades ocorreriam lentamente, atuando na esfera da longa duração.

O historiador italiano Giovanni Levi percebeu por meio da análise dos registros de compra e venda de terras, que havia um mercado de terras já no século XVII na localidade de Santena, norte da Itália, e que o mesmo era imperfeito, ou seja, que não obedecia a uma racionalidade moderna a qual viria a padronizar os preços das

${ }^{22}$ ELIAS, Norbert. Introdução à sociologia. 3. ed. Lisboa: Edições 70, 2011.

${ }^{23}$ Grupos sociais resultantes das relações de interdependência entre seus componentes. Somente ao examinar cada interação entre os membros de uma unidade é que seria possível entender sua formação, as características de seus participantes, bem como os objetivos do grupo e de seus membros. Cada uma dessas unidades compósitas está envolvida em um jogo social, o qual segue modelos diferenciados de acordo com as escolhas e finalidades a serem alcanças por cada composição. ELIAS, Introdução à sociologia..., p. 70.

${ }^{24}$ ELIAS, Introdução à sociologia..., p. 81.

${ }^{25}$ GROSSI, Paolo. Historia da propriedade e outros ensaios. Rio de Janeiro: Renovar, 2006, p.16 e p. 55-56. 
terras, pois estava repleto de ligações parentais e de amizades ${ }^{26}$. Por meio deste estudo, Levi atenta a todos aqueles que trabalham com as relações sociais referentes à terra, sobre a necessidade de relacionar fatores econômicos ao cultural e político, pois: "o fluxo material dos bens, da terra em particular, sanciona as relações sociais $e$ é condicionado por elas" 27 .

O crescente número de pesquisas sobre família no período colonial colaborou para lançar luz sobre o papel das mulheres no que diz respeito à reprodução social $e$ material. Trata-se de perceber a mulher como um elemento componente da lógica familiar do Antigo Regime, na qual o estabelecimento de casamentos era um laço fundador para a formação, e perpetuação de famílias, não somente pela reprodução biológica, mas, principalmente social, linhagística. Tal laço dizia respeito à escolha dos pares que se entrelaçariam com a família. Era, portanto, a oportunidade das famílias de estreitarem vínculos com determinados grupos sociais, visando a manutenção de seus interesses, fossem estes simbólicos, como garantir a limpeza do sangue, fossem para corroborar o status social da mesma. Os casamentos ainda poderiam ser estabelecidos para resolver possíveis pendências ou querelas - como em alguns casos de partilha de herança e sucessão de bens.

Segundo Philippe Ariès, no Antigo Regime, a família era confundida com o patrimônio e a própria reputação da mesma ${ }^{28}$. Nessa perspectiva, compreende-se que a propriedade seria o suporte garantidor da sucessão e continuidade da família. Sendo necessário atentar para a importância de analisar o desdobramento da acumulação de bens, manutenção, transmissão e/ ou perda de bens por parte de famílias para que se compreenda a inserção e mutação social das mesmas. Foi neste desenvolver de pesquisas sobre a reprodução social $e$ as atribuições da mulher que surgiu na última década pesquisas que se dedicaram a analisar o papel da mulher no tocante à reprodução de bens materiais, referentes ao acesso, a posse e a gestão de bens por mulheres. Em linhas gerais, trata-se da análise da criação e da aplicabilidade de leis que regiam sobre a posse de bens, bem como ainda das arbitrariedades cometidas pelos indivíduos.

As mulheres do reino de Portugal e de suas colônias tiveram grandes dificuldades em adquirir liberdade acerca dos seus atos, pois, quando solteiras, estavam sob o julgo de seu pai e, quando casadas, passavam para julgo do marido. Tratava-se de uma sociedade baseada no poder pátrio, o qual era assistido culturalmente e juridicamente por meio do discurso da incapacidade feminina ${ }^{29}$. Em contrapartida às restrições, tal pressuposição favorável a erros por parte da mulher também gerava, ao menos em termos jurídicos, algumas proteções para a mesma, não podendo esta ser presa por dívidas, nem degredada ${ }^{30}$.

É nesse contexto de limitações impostas a mulher que serão analisadas as atuações das mesmas enquanto proprietárias e gestoras de bens. Nesse aspecto se destacam

\footnotetext{
${ }^{26}$ LEVI, Giovanni. A herança imaterial: trajetória de um exorcista no Piemonte do século XVII. Tradução de Cynthia Marques de Oliveira. Rio de Janeiro: Civilização Brasileira, 2000, p. 152-155.

${ }^{27}$ LEVI, A herança imaterial..., p. 155.

${ }^{28}$ ARIÈS, Philippe. História social da criança e da família. Rio de Janeiro: Zahar, 1978, p. 213-250.

${ }^{29}$ AMARAL, Isabela Guimarães Rabelo do. Inferiorizando mulheres no período imperial brasileiro: a influência do direito. In: XXVI Simpósio Nacional de História-Anpuh: 50 anos, São Paulo, 2011.

${ }^{30}$ WEHLING \& WEHLING, "O Direito de Família...", p. 158.
} 
condicionantes sociais acerca da mulher, os quais eram variáveis devido aos diferentes estatutos sociais e jurídicos aplicados aos diferentes estratos sociais, sobretudo, entre "donas" e "plebeias" ${ }^{1}$. As donas, que seriam as mulheres nobres", as quais teriam tirado prova de nobreza ou pertenciam a grupos legitimados socialmente $e^{33}$, adquiriam tal condição por via masculina, por casamento ou ascendência $^{34}$. Embora não houvesse necessariamente diferença quanto ao nível de fortuna das "donas" e "plebeias" - visto que mulheres do primeiro e do segundo grupo foram igualmente proprietárias de bens, como também chegaram aos limites da pobreza - aponta-se que as mulheres de condição social superior quando se tornavam viúvas poderiam obter maior autonomia ${ }^{35}$.

Com a viuvez restavam às mulheres poucas opções: ingresso em conventos ou recolhimentos; concepção de novo matrimônio, pelo qual a mulher perdia a gerência dos bens e dos filhos para o novo marido; ou assumir a gerência dos bens da família. Quando da morte do marido, não havendo filhos, a viúva ficava com a sua meação, prevista pelas Ordenações Filipinas ${ }^{36}$. A outra metade era destinada para quem o defunto houvesse determinado. Havendo filhos maiores, era realizada a divisão da herança, ou ficava a viúva de posse de tudo até sua morte quando todos os filhos $e$ filhas assim concordavam. Quando havia filhos menores, necessariamente um juiz de órfãos inventariava os bens e um tutor era indicado ${ }^{37}$. A viúva poderia ser a tutora desde que o solicitasse por provisão régia, a qual ainda deveria ser confirmada pelo Desembargo do Paço caso os bens inventariados excedessem o valor de 60\$000 réis $^{38}$. Foi devido a esta possibilidade que grande parte das mulheres proprietárias $e$ gestoras de bens da América portuguesa tratavam-se de viúvas.

Os trâmites após a morte do marido colocavam em risco a estabilidade financeira da família, pois além do elevado custo da realização do inventário havia as despesas fúnebres e religiosas, acertos de dívidas do defunto e, por fim, a divisão dos bens

${ }^{31}$ SILVA, Maria Beatriz Nizza da. Donas e plebeias na sociedade colonial. Lisboa: Editora Estampa, 2002.

${ }^{32}$ Segundo Raphael Bluteau, "dona" é atribuído à nobreza. Nobre seria aquele que por descendência ou por alvará régio se diferencia dos plebeus e mecânicos por honras. BLUTEAU, Raphael. Vocabulario portuguez \& latino: aulico, anatomico, architectonico ... Coimbra: Collegio das Artes da Companhia de Jesus, $1712-1728.8$ v. p. 287 e 730.

${ }^{33}$ O termo "nobreza da terra" e demais variações como "principais da terra" e "nobreza principal da terra", no século XVI designava no reino um conjunto de famílias advindas do Terceiro Estado, cuja ocupação de cargos honrosos justificava-se pela sua antiguidade na localidade. Dessa forma, tal termo transposto para a América portuguesa designava aqueles povoadores cuja ancestralidade remetiam a conquista da terra. FRAGOSO, João. "Nobreza principal da terra nas Repúblicas do Antigo Regime nos trópicos de base escravista e açucareira: Rio de Janeiro, Século XVII a meados do século XVIII". In: FRAGOSO, João \& GOUVÊA, Maria de Fátima (orgs.). Coleção o Brasil colonial: 1720-1821. Rio de Janeiro: Civilização brasileira, 2014, p. 175-177. MAGALHÃES, Joaquim Romero. Algarve econômico durante o século XVI. Lisboa: Cosmos, 1970.

${ }^{34}$ SILVA, Donas e plebeias..., p. 63.

${ }^{35}$ SILVA, Donas e plebeias..., p. 76-87.

${ }^{36}$ 1603. Livro 4, título 48, fl.833.

${ }^{37}$ SILVA, Maria Beatriz Nizza da. "Mulheres e patrimônio familiar no Brasil". Acervo, Rio de Janeiro, vol. 9, n. 1-2, jan./dez. 1996, p. 65.

${ }^{38}$ CHEQUER, Raquel Mendes Pinto. Negócios de família, gerencia de viúvas: senhoras administradoras de bens e pessoas (Minas Gerais1750-1800). Dissertação (Mestrado em História). Universidade Federal de Minas Gerais. Belo Horizonte, 2002, p. 63. 
deixados. A divisão do espólio, contudo, não era regra, pois, por vezes, as viúvas requeriam a tutela dos filhos para evitar o esfacelamento do patrimônio familiar, fato este recomentado por muitos dos defuntos ${ }^{39}$. As viúvas em alguns casos solicitaram o adiamento do prazo da divisão dos bens ${ }^{40}$.

Nas Minas Gerais vários homens articularam estratégias para tentar assegurar a unidade do patrimônio familiar nas mãos de suas senhoras. Foi comum, por exemplo, que se utilizassem de prerrogativa existente nas Ordenações Filipinas que garantia a liberdade de compra e venda de bens e vendiam o patrimônio do casal à própria esposa; assim, esta poderia prosseguir com os negócios da unidade familiar no caso da morte do marido. $\mathrm{O}$ contrato de venda permitia que os filhos recebessem suas partes legítimas somente após a morte da mãe, ou seja, tratava-se de tornar os bens da família indivisíveis por um período ${ }^{41}$.

As questões patrimoniais não se centravam somente na figura da viúva. Para estabelecer bons casamentos entre famílias de igual distinção social, bem como para garantir a sobrevivência das filhas, fazia-se necessário bons dotes. O dote por tratar-se de um adiantamento da herança da filha, variava de acordo com a fortuna dos progenitores. Tratava-se de dinheiro, joias, escravos, bens de raiz e, em casos singulares, hábitos e tenças em Ordens Militares, bem como propriedades de ofício ${ }^{42}$.

Quando órfãos, os filhos $e$ as filhas recebiam suas heranças somente quando atingissem a maior idade, ou seja, 25 anos, ou quando se emancipavam, mediante provisão do Desembargo do Paço. A emancipação não só possibilitava a gerência de seus bens, como também dispensava a autorização para casamentos. Tal situação propiciava às mulheres melhores condições de ingresso no "mercado matrimonial", visto que a herança suprimia o dote $e^{43}$, mas também possibilitava que tais mulheres gerissem seus próprios bens.

Maria Beatriz Nizza da Silva apontou uma característica comum às mulheres de melhores condições sociais da América portuguesa: a defesa de seus bens perante maridos aproveitadores e dilapidadores. Verificou vários casos de mulheres que solicitaram sua separação dos maridos no Tribunal Eclesiástico e partilha dos bens devido à má gerência sobre estes; e de realização de casamentos por meio de escrituras de arras, equivalente à separação de bens originais dos cônjuges, para evitar que o marido fizesse mau uso do dote da esposa ${ }^{44}$.

Algo em comum que permeia a recente historiografia produzida sobre as mulheres gestoras de bens é o caráter desbravador e povoador em diferentes contextos. Eni Samara, em Famílias, mulheres e povoamento, analisou o papel das mulheres nos primórdios do povoamento paulista, século XVII. A posse da terra e de escravos

${ }^{39}$ CHEQUER, Negócios de família..., p. 89-93.

${ }^{40}$ LEWKOWICS, Ida \& GUTIÉRREZ, Horácio. "As viúvas em Minas Gerais nos séculos XVIII e XIX". Revista do Curso de Pós-Graduação em História, Franca, vol.4, n. 1, 1997, p. 140.

${ }^{41}$ CHEQUER, Negócios de família..., p. 90.

${ }^{42}$ ALMEIDA, Suely Creusa Cordeiro de. "Mulheres e cotidiano no mundo português no século XVIII: entre normas e práticas". In: Anais do XXVI Simpósio Nacional de História. ANPUH: São Paulo, julho 2011. DUTRA, Francis A. "Os dotes dos hábitos das Ordens Militares de Santiago e Avis em Portugal e no Brasil do século XVII". In: SILVA, Sexualidade, família..., p. 163-176.

${ }^{43}$ SILVA, "Mulheres e patrimônio...", p. 89.

${ }^{44}$ SILVA, Donas e plebeias..., p. 72-74. 
significava prestígio e poder, de forma que as alianças matrimoniais entre aquela elite garantiam a continuidade do modelo social vigente ${ }^{45}$. Entretanto, a população masculina dessa época vivia em constante movimento, tratavam-se dos bandeirantes, responsáveis pela busca de riquezas minerais, pelo aprisionamento indígena para escravização e extermínio de quilombos. Tal situação teria delegado às mulheres viúvas ou de maridos ausentes a direção $e$ o provimento da casa ${ }^{46}$.

A historiadora Marize Helena de Campos evidenciou em sua tese, Senhores Donas: economia, povoamento e vida material em terras maranhenses (1755-1822), que na segunda metade do século XVIII, no Maranhão colonial, havia muitas mulheres proprietárias de terras, articuladas com a pecuária e, sobretudo, com a agricultura do algodão. Tais mulheres foram ainda caraterizadas enquanto desbravadoras das terras no processo de ocupação e povoamento das mesmas. Um dado interessante e peculiar desta pesquisa é a verificação de que mais da metade das mulheres proprietárias eram solteiras, sendo, portanto, regidas por ordenamento diferenciado das viúvas ${ }^{47}$.

Em A "Dona" do Sertão, Alexandre Souza analisou por meio da trajetória de dona Maria da Cruz, a forma como uma mulher teve papel central na manutenção do patrimônio familiar e na defesa dos interesses de sua prole. Dona Maria, natural da comarca das Alagoas, capitania de Pernambuco, membro de influente família daquela localidade, viveu desde finas do século XVII no médio São Francisco, nas confrontações com Minas Gerais, nas ditas novas terras de oportunidade. Sua família atuou na atividade pecuária para abastecimento da região mineradora. Após o falecimento do marido, passou a gerir os bens da família e, neste contexto, participou juntamente com os filhos em 1736 nas sedições, chamadas Motins do Sertão, contra o novo sistema de capitação de tributos que diminuía os lucros obtidos da pecuária ${ }^{48}$. $\mathrm{O}$ aspecto desbravador, ou seja, da conquista e ocupação de terras, conforme apontado para as capitanias de São Paulo, Rio de Janeiro, Minas Gerais e Maranhão, também foi pertinente nas capitanias do Norte como se verá a seguir.

\section{Mulheres Proprietárias nas Capitanias do Norte}

As mulheres também foram essenciais para povoar e tornar as terras produtivas nas capitanias do Norte, sobretudo, as devastadas pelas guerras contra indígenas. Carmen Alveal e Marcos Fonseca destacaram a participação feminina no povoamento do sertão das capitanias do Rio Grande e Ceará entre finais do Seiscentos e início do

${ }^{45}$ ARAÚJO, Regina Mendes de. "Mulheres das Minas Gerais proprietárias de terras e escravos, 17181760". Anais do XII Encontro Regional de História, ANPUH-RJ, 2006.

46 SAMARA, Eni de Mesquita. Famílias, mulheres e povoamento: São Paulo, século XVII. Bauru: EDUSC, 2003.

${ }^{47}$ CAMPOS, Marize Helena de. Senhores donas: economia, povoamento e vida material em terras maranhenses (1755-1822). Tese (Doutorado em História). Universidade de São Paulo. São Paulo, 2008.

${ }^{48}$ SOUZA, Alexandre Rodrigues de. A "Dona" do Sertão: mulher, rebelião e discurso político em Minas Gerais no século XVIII. Dissertação (Mestrado em História): Universidade Federal Fluminense. Niterói, 2011. 
Setecentos no contexto da Guerra dos Bárbaros $^{49}$, evidenciando uma maior incidência de solicitações de sesmarias ${ }^{50}$ por parte das mulheres naquele período em detrimento de todo o restante do período colonial naquelas capitanias ${ }^{51}$.

Estes historiadores perceberam que de um total de 5.251 sesmarias concedidas entre 1650 a 1850 para as capitanias do Norte, 373 foram concedidas a mulheres, ou seja, 7,10\%, sendo 297 solicitadas em conjunto com homens, e 77 solicitadas unicamente por mulheres. Uma justificativa recorrente usada pelas sesmeiras era a alegação de serem "descobridoras das terras" e que já ocupavam a mesma, o que evidencia a identidade de tais mulheres enquanto conquistadoras e povoadoras de terras $^{52}$.

Ana Alencar, em sua dissertação Declaro que sou "dona", viúva e cabeça de casal, analisou ao longo do século XVIII $e$ início do XIX as atuações das viúvas no povoamento do sertão de Quixeramobim, capitania do Ceará, o que foi efetivamente consolidado somente durante a segunda metade do século XVIII. As famílias que moravam nas ribeiras do rio Banabuiú-Quixeramobim, articuladas a atividade pecuária, tiveram diferentes percursos ao que diz respeito ao estado de viuvez feminina. Houve aquelas que casaram novamente, perdendo o direito de administrar seus bens; outras permaneceram administrando sua fazenda até sua morte; enquanto outras venderam seus bens para se sustentar no período de seca ${ }^{53}$.

A pecuária $e$ as atividades derivadas destas, principalmente ao que diz respeito ao tratamento do couro, também foi alvo da atuação de mulheres. Das 77 solicitações de sesmarias realizadas unicamente por mulheres nas capitanias do Norte, 52 usaram como justificativa a posse de gado, o que evidencia a relação de tais mulheres com a pecuária ${ }^{54}$. Na capitania de Pernambuco, constatou-se que, em meados do século XVIII, havia cinco fábricas de atanados, e mais 22 de curtume, das quais três eram propriedade e administradas por mulheres, Dona Antônia de Lima Mello, e a viúva Tereza de Jesus, a qual possuía duas fábricas ${ }^{55}$.

${ }^{49}$ Trata-se de um conflito entre etnias indígenas, conquistadores e milícias no Assu, capitania do Rio Grande, travados entre 1698 e 1720, decorrente do processo de ocupação portuguesa daquele espaço. Ver mais em: PUNTONI, Pedro. A Guerra dos Bárbaros: povos indígenas e a colonização do Sertão Nordeste do Brasil, 1650-1720. São Paulo: Hucitec; EDUSP; FAPESP, 2002. SILVA, Tyego Franklin da. A ribeira da discórdia: terras, homens e relações de poder na territorialização do Assu colonial (1680-1720). Dissertação (Mestrado em História). Universidade Federal do Rio Grande do Norte. Natal, 2015.

50 Sistema de concessão de terras criado em 1375, implantado na América portuguesa para o povoamento e exploração da mesma. ALVEAL, Carmen Margarida Oliveira. Converting land into property in the Portuguese Atlantic World, 16th-18th Century. 2007. Tese (Doutorado em História). Johns Hopkins University. Baltimore, 2007.

${ }^{51}$ ALVEAL, Carmen Margarida Oliveira \& FONSECA, Marcos Arthur. "Flores do sertão: mulheres das Capitanias do Norte e suas estratégias para assegurar seu quinhão de terras (1650-1830)". In: MORGA, Antônio Emilio (org.). História das Mulheres do Norte e Nordeste Brasileiro. São Paulo: Alameda, 2015, p. 148-149.

${ }^{52}$ ALVEAL, \& FONSECA, "Flores do sertão...", p. 157-158.

53 ALENCAR, Ana Cecília Farias de. Declaro que sou "dona", viúva e cabeça de casal: mulheres administradoras de bens nos sertões de Quixeramobim (1727-1822). Dissertação (Mestrado em História). Universidade Federal do Ceará. Fortaleza, 2014.

${ }^{54}$ ALVEAL \& FONSECA, "Flores do sertão...", p. 157.

${ }^{55}$ INFORMAÇÃO Geral da Capitania de Pernambuco [1749]. Anais da Biblioteca Nacional, vol. XXVIII, 1908, p. 479-481. 
Pesquisas recentes têm evidenciado a migração de indivíduos da área litorânea para o sertão desde o final do século XVII por meio da pecuária, como consequência da necessidade de ocupar o sertão e combater invasões de estrangeiros. Destaca-se também, que a pecuária possuía um mercado muito dinâmico, sendo fundamental para o abastecimento das zonas açucareiras ${ }^{56}$. As gestoras de bens da América portuguesa não diziam respeito somente a proprietárias de terras envolvidas na pecuária, mas também a mulheres engajadas no processo de produção do açúcar por meio da posse e administração de engenho.

Verificou-se por meio de um conjunto de fontes $^{57}$ que, para a capitania de Pernambuco, havia mulheres proprietárias de engenhos desde os primórdios de sua colonização. Apurou-se que no século XVI havia seis mulheres proprietárias de engenhos, sendo possível identificar entre elas, cinco viúvas e uma dona. Destaca-se destas, pela perpetuação de sua linhagem até pelo menos finais do século XVIII, Brites de Mendes Vasconcelos, viúva de Arnau de Holanda, a qual herdou o engenho do falecido marido, Santo André, e fundou um novo, chamado São José, dos quais foi administradora na década de 1630 .

No século XVII o número de mulheres proprietárias foi muito maior: 38. Tal crescimento está diretamente relacionado ao período de dominação holandesa naquela localidade. Neste período, principalmente no momento da invasão, 1630, e da Restauração, 1645-1654, muitos homens morreram nos conflitos armados. A alta mortalidade gerou a necessidade de que as mulheres gerissem seus bens e/ou os da família quando possível. No século XVII, cuja estimativa do número total de engenhos era cera de $130^{58}$, verificou-se que durante algum período 38 mulheres foram proprietárias, ou seja, $29 \%$, sendo destas: 23 viúvas; 5 administradoras de suas heranças; 3 mulheres casadas proprietárias e administradoras; e de 7 não se obteve mais informações. Destas 38 mulheres verificou-se ainda que 10 possuíam o título de dona, ou seja, se tratavam de mulheres ligadas à nobreza da terra local. Durante o século XVII, apuraram-se ainda casos de mulheres que administravam os engenhos juntamente com seus maridos, como foi o caso de Dona Clara das Neves, esposa de Gaspar Dias Ferreira, administradores do engenho São José, em $1650^{59}$. Há ainda

${ }^{56}$ SILVA, Kalina Vanderlei. Nas solidões vastas e assustadoras: a conquista do sertão de Pernambuco pelas vilas açucareiras nos séculos XVII e XVIII. Recife: CEPE, 2010. SILVA, Rafael Ricarte da. Formação da elite colonial nos sertões de Mombaça: terra, família e poder (Século XVIII). Dissertação (Mestrado em História). Universidade Federal do Ceará. Fortaleza, 2010. ROLIM, Leonardo Cândido. "Tempo das carnes" no Siará Grande: dinâmica social, produção e comércio de carnes na vila de Santa Cruz do Aracati (c.1690-c.1802). Dissertação (Mestrado em História): Universidade Federal da Paraíba. João Pessoa, 2012.

${ }^{57}$ GOUVÊA, Fernando Cruz. "Uma relação de engenhos de Pernambuco e Paraíba no século XVIII". Revista Brasil Açucareiro, ago. 1971, p. 78-84. FONSECA, Antonio José Victoriano Borges da. Nobiliarquia Pernambucana. 2 vols. Rio de Janeiro: Biblioteca Nacional, 1935 [1883]. MELLO, Evaldo Cabral de. O bagaço da cana: os engenhos de açúcar do Brasil holandês. São Paulo: Penguin Classics; Companhia das Letras, 2012. Arquivo Histórico Ultramarino - Papéis Avulsos. AHU-PE, Cx.50, D. 4421.

${ }^{58}$ LISBOA, Breno Almeida Vaz. "Engenhos, açúcares e negócios na capitania de Pernambuco (c.1655 c.1750)". CLIO Revista de Pesquisa Histórica, vol. 32, n. 1, 2014, p. 197.

${ }^{59}$ MELLO, O bagaço da cana..., p. 89. 
um caso de sociedade criada em 1636 por Bartolomeu Lins com sua mãe, Dona Adriana de Almeida Lins, e sua sobrinha Jerônima de Almeida ${ }^{60}$.

No século XVIII, cuja estimativa do número total de engenhos era mais elevada, de 228 para meados do século, verificou-se, todavia, uma redução do número das mulheres posseiras/ gestoras de engenhos: 14, sendo destas nove donas e oito viúvas $^{61}$. Observa-se desta forma uma diminuição do número de mulheres proprietárias e administradoras de engenho, fato este possivelmente relacionado com a instabilidade do período de dominação holandesa. Porém, a continuidade, mesmo que em menor número, do desempenho desta atividade pelas mulheres é notória $e$ deve ser destacada.

Em Segredos internos, publicado em 1985, o brasilianista Stuart Schwartz analisou a produção açucareira da Bahia do século XVI ao XIX. Neste estudo, o autor refletiu sobre alguns pontos importantes a respeito da propriedade. Segundo Schwartz, os senhores de engenho buscavam deter o poder sobre suas terras por questões não apenas econômicas, mas também sociais, pois visavam afastar possíveis indivíduos que confrontassem seu poder, e muitas vezes por medida conciliatória arrendavam pequenas áreas de suas propriedades a fim de validar seu poder sobre a terra ${ }^{62}$.

Em Terra, trabalho e poder, publicado em 1988, Vera Lúcia Amaral Ferlini analisou documentos referentes ao engenho Sergipe do Conde, na Bahia, e demonstrou como a organização da terra, da propriedade, e da posição predominante dos senhores de engenho asseguraram a concentração da renda e a hierarquia necessária para o funcionamento do "sistema colonial", subordinando os lavradores de cana-de-açúcar. Ferlini avançou nas interpretações de Schwartz acerca dos usos da propriedade, sobretudo dos aforamentos, pois buscou compreender como os aforamentos, as enfiteuses, e o sistema sesmarial, funcionavam jurídica e empiricamente. Ao comparar as ordenações, alvarás, e as práticas dos usos da terra tanto por parte dos senhores de engenho como dos lavradores dos partidos de canade-açúcar, Ferlini sugeriu um panorama de conflitos sociais tramados por disputas pela terra ${ }^{63}$.

Em continuidade desta perspectiva acerca da complexidade da propriedade, a historiadora Márcia Maria Menendes Motta defendeu sua tese em 1996, Nas fronteiras do poder: conflito e direito à terra no Brasil do século XIX. Essa pesquisa marcou o início dos estudos direcionados a uma história social da propriedade. Nesta obra, Motta percebeu, por meio das análises dos registros paroquiais, e também da ausência deles, juntamente com antigos títulos de sesmarias, que era costume as práticas irregulares de acesso à terra, sobretudo, por parte dos grandes proprietários ${ }^{64}$.

Dessa forma, percebe-se que para analisar qualquer dinâmica de acesso à terra, que envolvam grandes ou médios senhores proprietários de terra na América

\footnotetext{
${ }^{60}$ MELLO, O bagaço da cana..., p. 139.

${ }^{61}$ GOUVÊA, "Uma relação...", p. 78-84. FONSECA, Nobiliarquia Pernambucana.

62 SCHWARTZ, Stuart B. Segredos internos: engenhos e escravos na sociedade colonial, 1550-1835. São Paulo: Companhias das Letras, 1988, p. 251.

${ }^{63}$ FERLINI, Vera Lúcia Amaral. Terra, trabalho e poder: o mundo dos engenhos no Nordeste colonial. São Paulo: Brasiliense, 1988, p. 156-157, p. 166-192.

${ }^{64}$ MOTTA, Márcia Maria Menendes. Nas fronteiras do poder: conflito e direito à terra no Brasil do século XIX. 2. ed. Rio de Janeiro: EdUFF, 2008, p. 167-190.
} 
portuguesa, deve-se compreender os jogos de interesses que cada um dos envolvidos articularam para assegurar as suas posses. Destaca-se, a exemplo destas articulações para manutenção da propriedade, a família Guedes Alcoforado. Esta família foi conhecida nas capitanias do Norte por sua presença desde antes do domínio holandês, por suas atuações em cargos administrativos, patentes militares $e$ ordenanças, e também pela posse de terras e de engenhos.

Todavia, na primeira metade do século XVIII, a família encontrava-se endividada. Na década de 1730, João Guedes Alcoforado era acusado de ser devedor da Fazenda Real na capitania de Itamaracá. Segundo o almoxarife daquela Provedoria, os antecessores dele não realizaram a cobrança da dívida de João devido à "intimidade" entre eles e devido à fama da família de que eram todos criminosos ${ }^{65}$. Contudo, as dívidas de João passaram e ser cobradas e seus engenhos Araripe de Baixo e São João Batista foram postos para a arrematação ${ }^{66}$. Entretanto, houve grande dificuldade para que estes fossem arrematados devido ao medo dos indivíduos de sofrerem ameaças da família Guedes Alcoforado ${ }^{67}$.

João tentou reaver a posse de seus engenhos por meio de solicitação de anulações de arrematação ${ }^{68}$. Com a morte de João, foi a sua viúva, Maria Dias de Abreu, que continuou solicitando a anulação ${ }^{69}$. Paralelamente, a família tentava garantir a posse de outras propriedades, como consta no pedido de demarcação de terras na capitania de Itamaracá, realizado por João de Guedes Alcoforado, filho homônimo, em $1747^{70}$. Possivelmente, a busca pela demarcação das terras de seus engenhos implicava em garantir a posse, o usufruto, o direito de arrendar a mesma, bem como evitar querelas pela posse das mesmas.

Aponta-se que durante o século XVIII, parece ter havido um acirramento pelas terras relacionadas ao fabrico do açúcar, fosse pelos engenhos, fosse pelos partidos de cana-de-açúcar. Destaca-se ainda, como já se evidenciou, que mesmo que a mulher não fosse detentora da posse e/ ou da gestão dos bens da família, ainda assim poderia atuar para a preservação do mesmo, como a caso da viúva Maria Dias de Abreu, que continuou solicitando a anulação da arrematação dos engenhos do falecido marido. Aponta-se com isto, que o mapeamento de trajetórias de mulheres proprietárias ou gestoras de bens podem com frequência ser dificultado pela falta de evidências documentais, como por vezes, pode ser percebida nas entrelinhas dos escassos registros, como fora o caso da viúva apontada.

Todavia, há casos da administração de mulheres impecavelmente documentados. Cristiane Veiga por exemplo, destacou uma viúva senhora de engenho muito bem sucedida na capitania do Rio de Janeiro nos finais do Setecentos, a qual teria conseguido sanar as dívidas do engenho e duplicar o número de escravos

${ }^{65}$ AHU-PE, Papéis avulsos, Cx. 43, Doc. 3871.

${ }^{66}$ AHU-PE, Papéis avulsos, Cx. 44, Doc. 3995. AHU-PE, Papéis avulsos, Cx. 67, Doc.5662.

${ }^{67}$ AHU-PE, Papéis avulsos, Cx. 44, Doc. 4023. AHU-PE, Papéis avulsos, Cx. 55, Doc. 4813.

${ }^{68}$ AHU-PE, Papéis avulsos, Cx. 45, Doc. 4083.

${ }^{69}$ AHU-PE, Papéis avulsos, Cx. 56, Doc. 4855.

${ }^{70}$ AHU-PE, Papéis avulsos, Cx. 66, Doc. 5620. Cabe apontar que o ato de demarcar as terras de engenhos na capitania de Pernambuco parece ter sido comum nesse período. Constam 44 solicitações de demarcação de terras de engenhos na capitania de Pernambuco entre 1710 e 1780 no Catálogo de papéis avulsos da capitania de Pernambuco do Arquivo Histórico Ultramarino. 
trabalhadores ${ }^{71}$. Maria Beatriz Nizza da Silva também analisou casos bem sucedidos de gerência de engenhos por mulheres para o início do século XIX na Bahia, evidenciando inclusive o conhecimento de técnicas inovadoras no trato das lavouras por parte de mulheres ${ }^{72}$.

\section{Considerações Finais}

Os estudos recentes demonstrados para as capitanias de Minas Gerais, São Paulo, Rio de Janeiro, Maranhão e as capitanias do Norte (Pernambuco, Itamaracá, Paraîba, Rio Grande do Norte e Ceará), mais as fontes aqui analisadas, revelam uma pluralidade e simultaneidade de atuações por parte de mulheres de diferentes estatutos sociais (nobres, não nobres, donas, viúvas, entre outras). Estas mulheres, em sua maioria membros da elite local, sobretudo, da nobreza da terra, atuaram como donas de terras, de fazendas, de engenhos, de escravos, de fábricas de curtume. Atuaram dessa forma no comércio, na pecuária e na agricultura. Podemos concluir que embora as atividades aqui analisadas fossem desempenhadas majoritariamente por homens, as mulheres em diferentes contextos e de variadas formas atuaram enquanto proprietárias e gestoras do patrimônio familiar.

Compreende-se que mesmo não sendo as atividades aqui elencadas exercidas em sua maioria por mulheres, cabe-nos o esforço de analisar e perceber quais foram as possibilidades de atuação percebidas pelas mulheres da América portuguesa diante de seus limitadores e condicionantes sociais. As mulheres conseguiram desenvolver um papel importante não apenas na reprodução social de suas famílias, por meio de casamentos, mas também na reprodução material de suas famílias, não se restringindo a casamentos para manter a integridade dos bens e dos interesses da família, mas também atuando como proprietárias, gestoras, defensoras de seus bens ou de suas famílias - e dos interesses de sua prole.

\section{socos}

${ }^{71}$ VEIGA, Cristiane Fernandes Lopes. "Senhoras de si: mulheres proprietárias no Rio de Janeiro setecentista (1763-1808)". In: Anais do XXVIII Simpósio Nacional de História. Florianópolis-SC, 27 a 31 de julho de 2015.

${ }^{72}$ SILVA, "Mulheres e patrimônio...", p. 95. 


\section{RESUMO}

Das várias possibilidades de estudo sobre gênero, destacar-se-á neste ensaio o papel das mulheres ao que diz respeito à manutenção social de seu grupo, sobretudo, ao que diz respeito à reprodução material. Para tal efeito, serão apontados, de forma sucinta, os estudos sobre gênero realizados para a América portuguesa $e$, em seguida, de forma mais específica, os estudos produzidos sobre a posse e gestão de bens por parte de mulheres, principalmente nas capitanias do Norte (Pernambuco, Itamaracá, Paraíba, Rio Grande do Norte e Ceará) do Estado do Brasil. Busca-se por meio desta análise evidenciar as possibilidades de atuação da mulher enquanto proprietária em meio aos seus limitadores sociais. Demonstrar-se-á que muitas mulheres (solteira e viúvas; nobres ou não) atuaram intensamente na pecuária, na produção de açúcar e na agricultura, demonstrando que, embora fossem atividades majoritariamente masculinas, havia espaço para a atuação de mulheres, sobretudo, quando estas defendiam os interesses de sua prole. Para tal serão ainda discutidas concepções de propriedade e de família.

Palavras Chave: Mulheres; Propriedade; América Portuguesa.

Artigo recebido em 14 nov. 2016.

Aprovado em 06 mar. 2017.
ABSTRACT
Of the various possibilities of study on gender, the role of women in relation to the social maintenance of their group, especially with regard to material reproduction, will be highlighted in this essay. To this end, the studies on gender carried out for Portuguese America and, more specifically, the studies on the possession and management of goods by women, especially in the northern captaincies (Pernambuco, Itamaracá, Paraíba, Rio Grande do Norte and Ceará), will be summarized. This analysis seeks to show the possibilities of women acting as owners in the midst of their social limiters. It will be shown that many women (single and widowed, noble or not) worked intensively in livestock, sugar production and agriculture, demonstrating that although they were mostly male activities, there was room for These defended the interests of their offspring. To this end, conceptions of property and family will be discussed.

Keywords: Women; Property; Portuguese America. 